\title{
New directions in parenting research.
}

\author{
Daniel Séguin \\ Department of Psychology, Mount Saint Vincent University, Canada.
}

Accepted May 26, 2016

Controversies regarding the influences of parenting on childhood development are well established. For some time, there had been an expanding sense that parents matter relatively little to a child's development [1]. In opposition is my ongoing research where evidence has been established that parental relations with children are of paramount importance [2-6]. Some other long-held parenting debates are controversial because of the assumed or founded impacts on children. One such area is the same vs. opposite sex parent debate.

The American Psychological Association (APA) asserted that "Not a single study has found children of lesbian or gay parents to be disadvantaged in any significant respect relative to children of heterosexual parents" [7]. Pioneering and contemporary research in the area were examined to make these claims [8-12] and the focus was mainly on traditional parenting behaviours (e.g. parental relationships) and child outcomes (e.g. externalizing behaviours and overt aggression). Other researchers hold the belief that we are at risk of overgeneralizing the available findings because of the limited scope of the current research field [13]. Researchers cite multiple methodological concerns to support their cautionary stance. In the current editorial it is argued that the investigation of similarities or differences between same and opposite sex parenting needs expansion vis a vis meta-emotion based parenting. Specifically, the social, emotional and cognitive outcomes for children based on their parents' union and corresponding metaemotional styles have never been established.

\section{Conceptualizing Meta Emotional Parenting Styles}

Gottman, Fainsilber, and Hooven and others have defined a new area of parenting with the theory of parental MetaEmotion [5,6,14,15]. Meta-emotion refers to an "organized set of feelings and cognitions about one's own emotions and the emotions of others" [15]. As such, Gottman and colleagues proposed two distinct parenting styles that emphasize increased versus decreased levels of metaemotion [14]. Emotion coaching (EC) parenting style is operationalized as a parent's awareness of emotions within themselves and their children and their ability to use this awareness to benefit their child's socialization and has been linked to better regulation abilities and well developed social and emotional abilities in children. Emotion dismissing (ED) parenting style refers to a lack of awareness and therefore a diminished ability to deal with children's emotions and has been linked with less advanced regulation abilities and weakened social and emotional abilities in childhood [5]. However, there have been no published accounts of the links between meta-emotion parenting styles and children's outcomes in situations represented by same-sex parenting. Furthermore, there is a noticeable lack of research to compare same and opposite sex parents on meta-emotion.

\section{Parenting and Social-emotional Outcomes}

There have been consistent findings in past studies pointing to direct linear associations between traditional parenting variables (e.g., disciplinary styles) and child outcomes [1618]. However, there has been little empirical examination of the importance of parental emotional styles in the direct relations with child-based characteristics and socialemotional outcomes. In the few studies published in the area, it was found that meta-emotion directly and indirectly impacts a variety of developmental outcomes for children $[5,14]$. In my current research, EC and ED parenting styles are conceptualized as the variables linked to other variables such as child-based characteristics and social-emotional and cognitive development. These linkages ae currently being tested within and between same and opposite sex parented families in a novel step towards expanding the research area.

\section{Parenting and Child-based Characteristics}

Emotion and behaviour regulation are child-based (internal) characteristics. Emotion regulation involves the control of impinging stimuli and internal states [18] and behavioural regulation refers to the ability to modulate the behavioural expression of impulses and/or feelings [19]. Gottman et al. argued that meta-emotional parenting behaviours are positively associated with children's regulatory physiology and the ability to regulate emotions $[14,15]$. In my current research, these variables are argued as being moderators to the main linkages. 


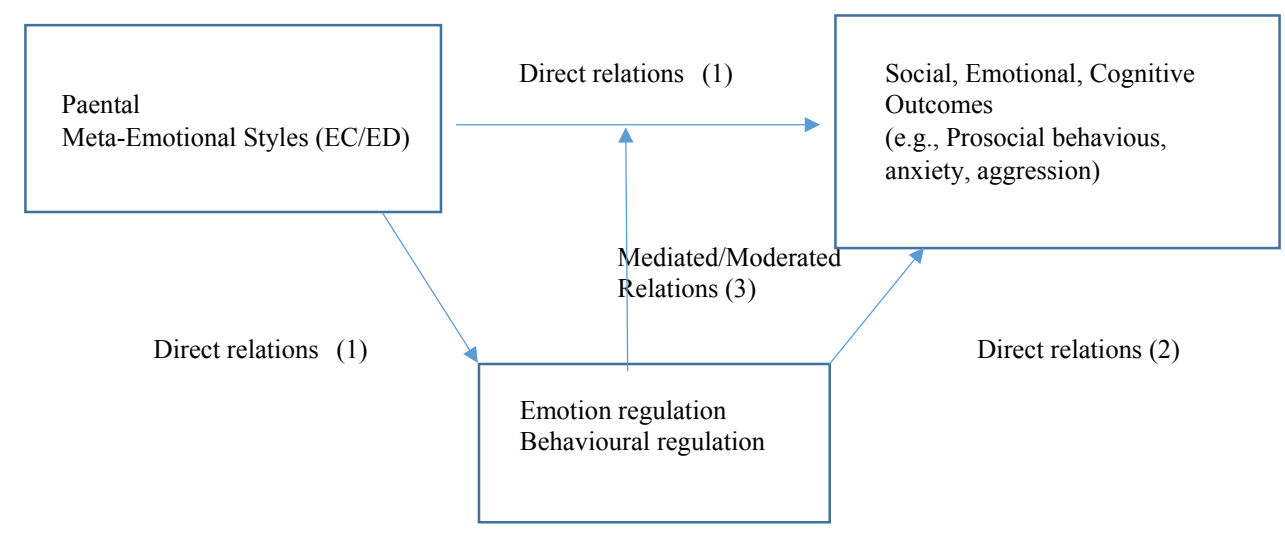

Figure 1: The path structure

\section{Regulation and Development}

Researchers have found that emotional and behavioural regulation impact on a number of social developmental domains [20]. Eisenberg et al. reported that socially appropriate behavior was positively related to high levels of behavioural nd emotional regulation [21]. However, there has been little empirical attention to the interaction of parenting and regulation in the prediction of socialemotional adjustment in samples of same and opposite sex parents. This idea echoes Goodness of Fit Model [2,22].

\section{Social-Emotional Adjustment}

Commonly, researchers determine adjustment in terms of the presence or lack of behaviour problems (e.g., anxiety and aggression) and pair that with evidence of prosocial behaviours (i.e., helping behaviours) $[2,5,23,24]$ to define social competence. Anxiety, aggression and prosocial behaviours based on teacher ratings and behavioural observations and are included as outcome variables in my research.

\section{The Path Structure and Hypotheses for Future Studies}

Thomas and Chess' foundational Goodness of Fit Model reports that a good fit exists when parenting and child characteristics are well matched [22]. To date, no studies have examined this Model as it may relate to the variables proposed herein in same and opposite sex parenting samples. I have hypothesized (Figure 1) that (1) an EC parenting style will be positively related to higher levels of emotion and behavioural regulation as well as higher social competence in childhood but negatively related to aggression and anxiety across the two samples. It is hypothesized that (2) a positive linear relationship will be found between the regulatory abilities of the child and social competence across the two samples. And, I also predicted that (3) moderated associations (interactions) will be found between parental emotional styles and regulation in the prediction of social-emotional developmental outcomes in childhood. Based on the existing literature I am expecting my research findings to show that (a) higher levels of ED parenting paired with higher regulatory abilities may not be associated with deleterious outcomes in childhood; (b) higher regulation may buffer children from the harmful effects of a potentially damaging parenting style; (c) higher levels of EC parenting style paired with low levels of regulation may predict positive outcomes in childhood. Overall, these relationships represent a "good fit" or a match between the parents' parenting style and the child's regulatory characteristics to predict social-emotional developmental outcomes. Because of the lack of attention in this particular area, it is with an exploratory approach that the variability between the two samples will be investigated. The bulk of the research suggests either no difference or increased meta-emotion in favour of samesex parenting. The following path structure represents a novel departure from currently available research and will pay dividends in terms of knowledge mobilization and dissemination in the field. With additional novel research studies in the area comes a better understanding of parental impact on child development. With this editorial, I encourage additional research.

\section{References}

1. Harris JR. The nurture assumption: Why children turn out the way that they do. The Free Press, New York 1995.

2. Hipson WE, Séguin DG. Goodness of fit model. Encyclopedia of personality and individual differences. Springer, New York 2016

3. Jones S, Lagacé-Séguin DG. I think I can't, I think I can't: Associations between parental pessimism and children's well-being. Early Child Development and Care 2006; 176: 849-865.

4. Lagacé-Séguin DG, Case E. Extracurricular activity and parental involvement predicts positive outcomes in elementary school children. Early Child Development and Care 2010.

5. Lagacé-Séguin DG, Coplan R. Parental emotional styles and child social adjustment: Assessment, correlates and outcomes in early childhood. Social Development 2005; 14 : 613-636.

6. Lagacé-Séguin DG, Gionet A. Parental meta-emotion and temperament predict coping skills in early adolescence. International Journal of Adolescence and Youth 2009. 
7. American Psychological Association. Brief on Lesbian and Gay Parenting. Washington, DC: APA 2005.

8. Anderssen N, Amlie C, Ytteroy E. Outcomes for children with lesbian or gay parents: A review of studies from 1978 to 2000. Scandanavian Journal of Psychology 2002; 43: 335351 .

9. Chan R, Brooks B, Raboy C, Pattersen C. Division of labour among lesbian and heterosexual parents: Associations with children's adjustments. Journal of Family Psychology 1998; 12: 402-419.

10. Cameron P, Cameron K. Homosexual Parents. Adolescence 1996; 31: 757-776.

11. Bos H, van Balen D. Experience of parenthood, couple relationship, social support, and child- rearing goals in planned lesbian mother families. Journal of Child Psychology and Psychiatry 2004; 45: 755-764.

12. Wainright J, Russell S, Patterson C. Psychospcial adjustment, school outcomes, and romantic relationships of adolescents with same-sex parents. Child Development 2004; 18861898.

13. Marks L. Same-sex parenting and children's outcomes: A closer examination of the American psychological association's brief on lesbian and gay parenting. Social Science Research 2010; 41: 735-751.

14. Gottman J, Fainsilber L, Hooven C. Parental meta emotion philosophy and the emotional life of families: Theoretical models and preliminary data. Journal of Family Psychology 1996; 10: 243-268.

15. Gottman J, Fainsilber L, Hooven C. Meta-Emotion: How families communicate. Hillsdale, NJ: Erlbaum 1997.

16. Baumrind D. Parental disciplinary patterns and social competence in children. Youth and Society 1978; 9: 239-276.

17. Dix T. Attributing dispositions to children: An interactional analysis of attribution in socialization. PSPB 1993; 19: 633643.

18. Goodnow J, Collins W. Development according to parents: The nature, sources, and on sequences of parent's ideas. Hove, England: Erlbaum 1990.

19. Eisenberg N, Fabes R. Mothers' reactions to children's negative emotions: Relations to children's temperament and anger behavior. Merrill-Palmer Quarterly 1996; 40: 138-156.

20. Caspi A, Henry B, McGee R, Moffitt T, Silva P. Temperamental origins of child and adolescent behavioural problems: From age three to fifteen. Child Development 1995; 66: 486-498.

21. Eisenberg N, Fabes R. The relation of young children's vicarious emotional responding to social competence, regulation, and emotionality. Cognition and Emotion 1995; 9: $203-228$

22. Thomas A, Chess S (1977) Temperament and Development. New York: Brunner/Mazel.

23. Coplan R, Wichmann C, Lagace-Seguin D, Rachlis L, McVey M. The "degree" of instructor education and child outcomes in junior kindergarten: A comparison of certificated teachers and early childhood educators. Journal of Research in Childhood Education 1999; 14: 78-90.

24. Coplan R, Gavinski MH, Lagace-Seguin D, Wichmann CG. When girls versus boys play alone: Gender differences in the relations between nonsocial play and adjustment in kindergarten. Developmental Psychology 2001; 37: 464474.

\section{Correspondence to:}

Daniel Séguin, Department of Psychology

Mount Saint Vincent University

Canada. 